\title{
A New Look at Cochlear Mechanics
}

\author{
Carole A Jardine \\ Department of Speech Pathology and Audiology \\ University of the Witwatersrand
}

\begin{abstract}
The spectacular discovery of otoacoustic emissions has led to a plethora of cochlear mechanic models, all attempting to explain the active, nonlinear processing of the cochlea suggested by these recordable responses. These hypothetical proposals have been largely based on animal experimentations, mathematically-based theorems, and observations in simulated environments. None have been irrevocably validated although there is much circumstantial evidence expounding their feasibility. Advances in electron microscopy, mechanical engineering, histological examination techniques together with the technology enabling us to measure these emissions, have radically altered the current views on the assumptions of auditory mechanics. This paper briefly contrasts the previously established cochlear theories proposed by doyens such as Helmholtz (1857) and von Békésy (1936) with current perspectives advanced by cell biologists and biophysicists. However, the exact nature of cochlear processing still remains a mystery. As numerous chasms of knowledge about audition are being filled, so even more questions are posed in a seemingly eternal quest for the answer!
\end{abstract}

\section{OPSOMMING}

Hierdie indrukwekkende ontdekking van otoakoustiese emissies het gelei tot 'n oormaat kogleêre-werkingmodelle wat almal gepoog het om die aktiewe nie-lineêre prosessering van die koglea wat deur optekenswaardige response voorgestel word, te verklaar. Hierdie hipotetiese voorstelle is grotendeels op diere-eksperimente, wiskundig gefundeerde stellings en waarnemings in gesimuleerde omgewings gebaseer. Nie een hiervan is onweerlegbaar bekragtig nie, alhoewel daar heelwat omstandigheidsgetuienis bestaan wat die uitvoerbaarheid daarvan verklaar. Vooruitgang op die gebied van elektromikroskopie, meganiese ingenieurswese, histologiese ondersoektegnieke, tesame met die tegnologie wat die meting van hierdie emissies moontlik maak, het die algemene opvattings oor die aannames van ouditiewe funksionering radikaal verander. Hierdie artikel vergelyk die voorheen opgestelde kogleêre teorieë wat voorgestel is deur doyens soos Helmholtz (1957) en von Békésy (1936) kortliks met die huidige perspektiewe wat deur bioloë en biofisici daargestel is. Die presiese aard van prosessering bly egter'nog steeds'n geheim. Namate talryke leemtes in die kennis van gehoor nog aangevul word, word selfs meer urae gestel in 'n oënskynlik nimmereindigende soeke na die antwoord!

\section{ABBREVIATIONS USED IN TEXT}

OAE

Otoacoustic emissions

EOAE Evoked otoacoustic emissions

DPOAE Distortion product otoacoustic emissions

BM Basilar membrane

IHC Inner hair cell

OHC Outer hair cell

RL Reticular lamina

OCN Oliviocochlear núcleus

ATP Adenosine triphosphate

\section{INTRODUCTION}

"Few areas of audiology have advanced as rapidly as cochlear physiology and biophysics have over the past decade. The advance began with the shock realisation that existing knowledge and accepted concepts could not explain the response of the cochlea to sound and in par. ticular otoacoustic emisssions. Our very understanding of both the physical basis of hearing and the nature of hearing impairment was challenged".

(Grandori, Cianfrone and Kemp, 1990, VIII)

As early as 1948, Gold (cited in Rossi, 1990) inarguably stated that the inner ear itself was a vibratory body and could therefore produce sound since it did not exist in a vacuum. However, instrumentation to measure this response had been slow to develop and his statements were largely ignored in favour of an exclusively sound-receiving cochlear, until the discov- 
ery of otoacoustic emissions (OAE) by David Kemp (1978).

Prior to this breakthrough, the ear was viewed as a passive transducer of sound and the idea that it could produce its own energy was inconceivable. Kemp (1978) changed this perspective radically when he presented his discovery of a response measurable within the closed external acoustic meatus, more than 5 milliseconds af ter excitation. He termed these responses "cochlear echoes" (Kemp, 1978, p.1386) also referred to as "Kemp echoes" (Johnstone, Patuzzi \& Yates, 1986, p.147) and currently called "otoacoustic emissions" (Probst, Antonellia \& Pieren, 1990, p.117; Glattke \& Kujawa, 1991, p.29; and numerous others). Upon his discovery, Kemp (1978) hypothesized that there could be an augmentation of energy from the cochlea which would result in a secondary disturbance of the middle ear and eardrum. By doing so, he implied that some active processing was occurring in the cochlea causing a major upheaval in the last decade of audiology.

Since then, the traditional model proposed by von Békésy (1936 cited by Zemlin, 1982) more than fifty years ago, has been expanded, manipulated, modified and at times rendered obsolete in the attempt to explain these OAE. Contemporary theories all aim to decipher the active, nonlinear, frequency selective processing of the cochlea. Each model has its own unique orientation often based on examination of isolated aspects of cochlear physiology. Unfortunately, none have been undeniably verified from research nor have these specialised viewpoints been amalgamated to form a cohesive model yet. Indeed, it would seem that the process of audition is one of the most poorly understood physiological systems in medicine today.

\section{OTOACOUSTIC EMISSIONS}

Using a signal averaging technique, a specially constructed acoustic probe and a broadband click stimulus, Kemp (1978) recorded the well-documented, large initial middle ear response ( 0 - $5 \mathrm{~ms}$ post stimulus) due to reflection of acoustical energy from the ear canal and tympanic membrane, as well as a much smaller response (5-62ms post stimulus) the hypothetical cochlear echo. Responses of a $1.5 \mathrm{cc}$ coupler with similar impedance characteristics to the human ear was compared to the human ear response as illustrated in Figure 1. He found that both showed rapid deterioration of response to almost zero approximately $6 \mathrm{~ms}$ post stimulus. However, the reappearance of a significant but much smaller response at about $10 \mathrm{~ms}$ post stimulus was unique to the human ear and found consistently amongst normal hearing subjects, and subsequently known as Evoked Otoacoustic Emissions (EOAE) (Kemp, 1978). Such evidence led to speculations about the active function of the cochlea.

Distortion Product Otoacoustic Emissions (DPOAE) were subsequently discovered a year later (Kemp, 1979). Distortion products are usually generated by systems which are nonlinear (Probst et al., 1990 ). Stimulation of the acoustic system by two primary frequencies $f_{1}$ and $f_{2}$ will undergo intermodulation distortion and a response is generated at frequencies other than the primary ones but at specific mathemati-

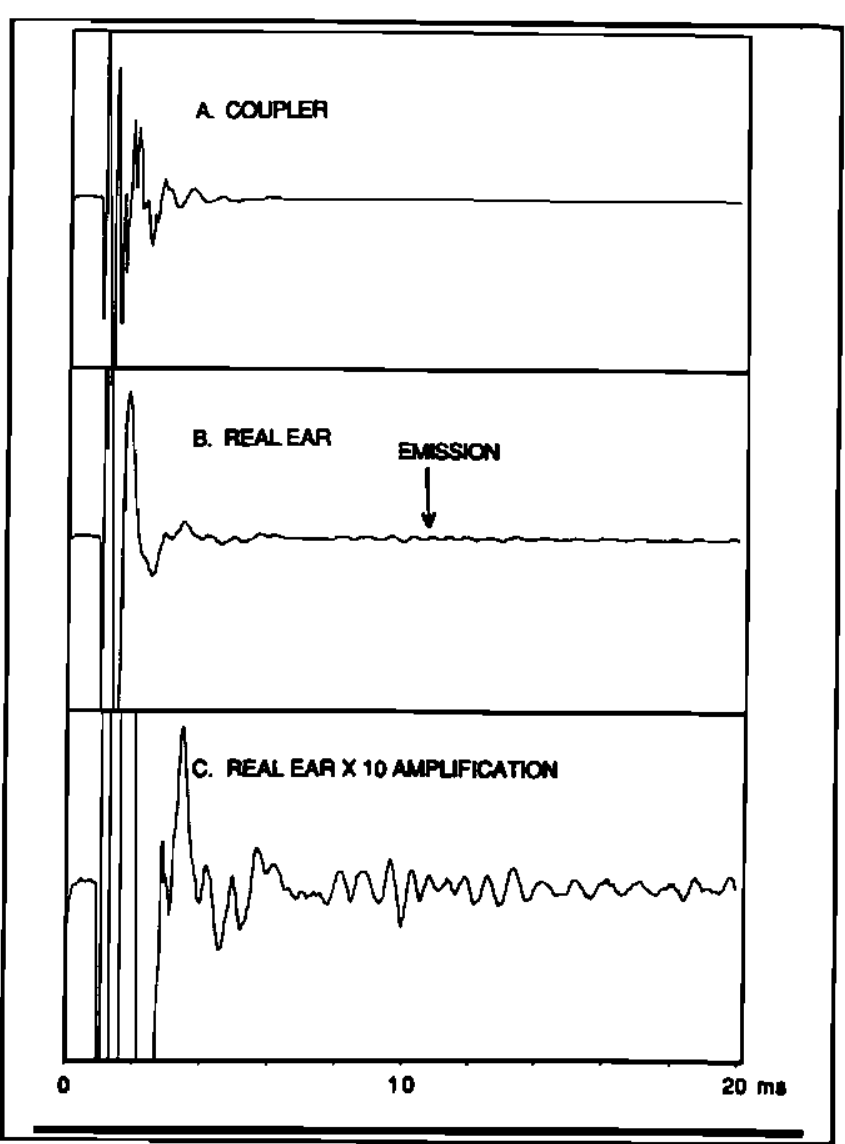

Figure 1. Comparison between responses recorded in a coupler $(A)$ and an adult human ear $(B)$ showing the much smaller response at about $6 \mathrm{~ms}$ poststimulus amplified in (C) (after Glattke \& Kujawa, 1991, p. 31).

cally-predictable frequencies ie. $f_{1}+f_{2}, f_{1}-f_{2}$ and the most robust at $2 f_{i}-f_{2}$ (Probst et al., 1990; Glattke \& Kujawa, 1991). Nonlinearity of the cochlea is strongly suggested by this distortion of the signal.

The third type of OAE differs from the previous two in that it is generated in the absence of any evoking stimuli and known as Spontaneous Otoacoustic Emissions (SOAE). They are measurable in approximately $40 \%$ of normal hearing people (Bright \& Glattke, 1986 cited in Glattke \& Kujawa, 1991) and are also thought to be representative of the active processes occurring in the cochlea.

The growth in technology together with the discovery of OAE has thus led the way towards a more objective, in situ measurement of the non-linear, active role of the cochlea and refocussed the attention of biologists, physiologists and audiologists.

\section{COCHLEA AS SOURCE OF EMISSIONS}

There was initial speculation that this response could be due to protracted reflections within the middle ear structures (kemp, 1978) but Glattke \& Kujawa (1991, p.29) refuted this concept because (a) the time delay of more than $6 \mathrm{~ms}$ is sufficient time for a sound wave to travel more than 6 feet; (b) the duration of the response is much longer than either the duration of the stimulus of the time for the middle ear response to decay; and finally (c) the stimulating clicks produced well-defined, 
frequency specific waveforms.

Johnson and Elbering (1982) in examining the clinical utility of OAE verified the cochlea as the source of these emissions by selecting two pathologies of known cochlear origin, that of aspirin toxicity and mumps. A moderate reversible salicylate-induced cochlear hearing loss was traced from pre-ingestion to two days following completion of the drug course. The initial bilateral emissions were reduced during the hearing loss but recovered fully after the drug was excreted suggesting to the researchers that the cochlea had recovered sufficiently. To ensure that these emissions were not an artifact of middle ear mechanisms, they tested a subject with complete anacusis in the right ear due to mumps. Emissions could not be measured in the right ear, even in the presence of normal recordings in the left. These experiments led the authors to believe that the OAE was of cochlear origin.

This paper aims to briefly outline the basic anatomy of the cochlea and the classic theory of cochlear mechanics, before examining current models focusing on the macro-functioning of wave propagation, the cochlear cellular responses, and finally the biochemical activity within the OHC.

\section{HISTORICAL PERSPECTIVE}

As early as 1857, Helmholtz (cited in Zemlin, 1982) proposed his resonance theory of hearing where he described the transverse fibres of the BM as being a bank of resonators. Then von Békésy (1960 cited in Clopton, 1986) was the first to formalise the one-dimensional travelling wave of the cochlea after extensive observations and experimentations spanning over half a decade (Kim 1986), for which he was awarded the Nobel Prize in Medicine and Physiology in 1961 (Zemlin, 1982). He postulated that spatial analysis of frequency information occurred as a result of the differential masses and stiffnesses along the length of the BM, each locus acting as a bank of resonators in a sense, but longitudinally coupled together by soft tissue (Clopton, 1986). Hydrodynamic forces within the fluids of the inner ear lead to displacement of the BM, and a shearing force between the RL and the tectorial membrane resulted in bending of the stereocilia and electromechanical transduction (Lim, 1986; Nuttall, 1986).

This view was supported by Zwislocki (1946 cited in Dancer 1992) and subsequen't scrutinies and analyses have verified this very acceptable theory. Yet, with the improvements in observation and model construction techniques, it appears that this macromodel of cochlear mechanics is now insufficient. The discrepancy between the broadly tuned data of the BM and the sharply sensitive auditory nerve was still confusing (Johnstone et al., 1986). Subsequently Evans and Wilson (1975 cited in Clopton, 1986) suggested that there was a "second filter" to sharpen the frequency selectivity of the cochlea. The nature of this second filter has been open to much conjecture, with ideas ranging from microresonance of the BM to the gradient differences of the BM displacements (Pickles, 1982). However, this concept of a second filter has generally been dismissed as being unnecesarry especially with the currently available experimental data (Kim, 1986).

Indeed, Lechner (1993) cautions against the use of passé models of BM motion because many models were based upon eclusively visual and often faulty observations. An example of such an occurrence is von Békésy's examination of longitudinal and radial fibres in the BM wherein he described that the incision of the BM resulted in openings in the shape of a cone (Zemlin, 1982; Lechner, 1993). One needs to bear in mind that several hours had elapsed between his observations and death of the tissue. Voldrich (1978) repeating these experiments soon after cell death, found that the shape was in fact more radial, only becoming conical 24 hours following death - the shape having far-reaching consequences in mathematical calculations. Furthermore, Nuttall (1986) highlights the poor instrumentation sensitivity used by von Békésy requiring intensity of at least 140dBSPL (Johnstone et al., 1986). Therefore, a plethora of models was based on incorrect observations of a cadaver basilar membrane (von Békésy, 1960 cited in Lechner, 1993) or following drainage of the scala tympani during preparation of an animal cochlea (Dancer, 1992).

\section{ACTIVE MACROMECHANICS IN THE COCHLEA}

The fundamentals of the travelling wave theory are generally still felt to hold true, that the cochlear is able to perform broad frequency analysis via differential displacement of the basilar membrane (Neely \& Kim, 1986). Nevertheless, the prevailing travelling wave theory has many limitations. It implies a cochlea which is a passive transducer to sound but if this was the case, it would be too highly damped to permit the sharp frequency selectivity to occur (Clopton, 1986). The linear system model also implies that one could predict the response to a click from a previously measured frequency response to tone stimulation (Eggermont, 1993, p.177), but this does not hold true and indeed, Geisler and Sinex (1983 cited in Eggermont, 1993) found that one could not even predict the response of a high intensity stimulus from that of a low intensity one. Such inexplicable evidence, together with the discovery of OAE and the ability of the cochlea to give rise to harmonic and intermodulation distortion and generate the DPOAE, suggests that: the previously accepted anatomical and physiological processes were wholly inadequate to explain nonlinearity of the cochlea (Eggermont, 1993) and that the inner ear was not as simple as first proposed by von Békésy in 1960 (Kim, 1986, p.105).

Kemp tentatively suggested that at very low levels of stimulation, there may be hyperexcitation at certain frequencies resulting in a recoil of the BM at "localised impedance discontinuities" $(1978$, p.1386) and the generation of the cochlea echo (1978). This postulation highlighted the possibility of the cochlea producing its own energy, sufficient to be transmitted retrograde through the middle ear and be generated within the ear canal. By constructing various cochlear models, several researchers have acknowledged the presence of 'some active element' to explain its fine tuning characteristics (Neely and Kim, 1986). Contemporary theories expounding the mechanically active cochlea tend to agree with this axiom and imply that the travelling wave is amplified by initiating or supplementing existing motion in the BM. 
Subsequent experimentation culminated in Davis (1983) presenting a revolutionary new model of cochlear mechanics in which - "an active process increases the vibration of the basilar membrane by energy provided somehow in the Organ of Corti" (p.79). He termed this active process "the cochlear amplifier: (p.80) but subsequent researchers have referred to it as "negative impedance" and "negative damping" (Neely \& Kim, 1986. p.1479), or "positive feedback" (de Boer, 1983, p.571).

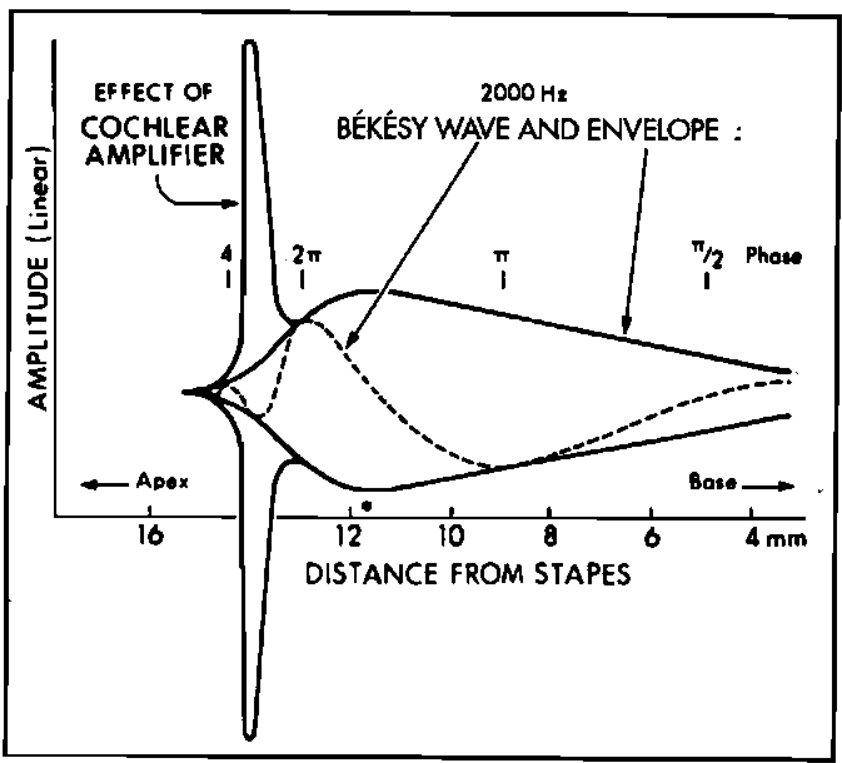

Figure 2. The classic travelling wave and its envelope is presented together with the cochlear amplifier. Note the frequency difference in amplitude peaks between the two (after Davis, 1983, p. 82).

The cochlear amplifier acts as a high-Q (good frequency resolution) acoustic resonator according to Davis (1983), such that it increases the sensitivity to lowthreshold stimuli, and sharp-tuning curves of a narrow segment of the BM. Figure 2 illustrates a travelling wave with its envelope to which is added the effect of this cochlear amplifier. It is interesting to note that the tip of the cochlear amplifier does not correspond with the maximum displacement of the travelling wave. This theorem has since been corroborated by Johnstone, Patuzzi \& Yates (1986) who generated travelling wave envelopes with increasing intensity and found that at high intensities, the maximum displacement shifted half an octave lower than the stimulating frequency citing this as another example of the nonlinear property of the cochlea. The well-documented frequency differences between the noise exposure and its resultant temporary threshold shifts (about one-half octave) may be used as further substantiating evidence (Davis, 1983, p.81).

From a hydrodynamic perspective, Kim,Siegel \& - Molnar (1979) on the other hand, proposed that the sharply tuned curves could occur as a result of negative damping along the crest of the travelling wave. By constructing a passive model of the cochlea, they observed a diffuse spread of energy through the fluid and assumed the total amount of energy entering the oval window was absorbed by the partition. In a contrasting active model, they constructed a negative damping partition just basal to the characteristic frequency, and hence energy in the form of eddy currents (according to Neely \& Kim, 1986) is released from this point of the partition, resulting in an increase in energy equivalent to $40 \mathrm{~dB}$ which was sharply focussed. Excessive gain at this point on the cochlear partition causes spontaneous oscillations of the hair cells thought to be the source of SOAE (Neely \& Kim, 1986).

Neely \& Kim (1986) in an attempt to combine the mechanical and hydrodynamic properties of the cochlea into a single cohesive model, suggested that the cochlear amplifier not only occurs as a result of BM displacement but that the loci of maximum displacement coincides with the greatest pressure difference between the two fluid-filled compartments. They imply that this pressure differential acted as a selective tuner. Von Békésy (1960 cited in Zemlin, 1982) also reported observing an eddy current at the locus of maximum displacement during his experiments.

\section{ACTIVE CELLULAR RESPONSES}

Although the mechanics of nonlinearity differ, there appears to be a consensus amongst researchers that "the BM vibration is very sharply tuned ... and is the predominant determinant in the major responses of the eighth nerve e.g., sensitivity, sharpness of tuning and many nonlinear functions" (Johnstone et al., 1986, 148).

Despite these different theories, researchers believed that the $\mathrm{OHC}$ were responsible for this active process in the cochlea (Clopton, 1986), and Davis (1983) and Bronwell (1990) postulated that it may be the energy source for the OAE measurable in the external ear canal. Noise, drugs (Glattke \& Kujawa, 1991, p.30), anoxia and mechanical insults (Davis, 1983, p.81) result in damage to OHC which then compromises the sensitivity (Harrison and Evans, 1979) and selectivity (Sellick et al., 1982 cited in Bronwell, 1990) of the cochlea, and can therefore be assumed to diminish or obliterate OAE recordings - a fact which has been verified through subsequent clinical trials.

Davis (1983) acknowledges that the active mocromechanism of the cochlea is very poorly understood and this has been the source of much debate. The motile properties of $\mathrm{OHC}$ are well accepted and it is popular to suggest that the lengthening or shortening of: OHC could either move the RL and BM further apart or closer together in order to deform the Organ of Corti and thereby produce the nonlinear response of the cochlea. Caution against such simplistic explanations is voiced by de Boer (1990). Through a series of mathematical computations based upon the 'sandwich model' (refer Figure 3), he proved that the motility of OHC would be unable to provide sufficient pressures to overcome the BM impedance and initiate motion.

Through observations and experimentations on the cat cochlea, Khanna, Ulfendahl \& Flock (1990) assumed that the sharply tuned curves of the BM were sourced by the OHC. In subsequent research, Khanna et al. (1990) were able to observe that the vibration amplitude and tuning characteristics for the $\mathrm{OHC}$ and the BM were different and concluded that they were independently controlled. The large vibration amplitude of: the OHC suggested that the OHC-induced movement in the BM and bony shell of the cochlear and not vice vers $\alpha$ previously supposed. Such observations give 


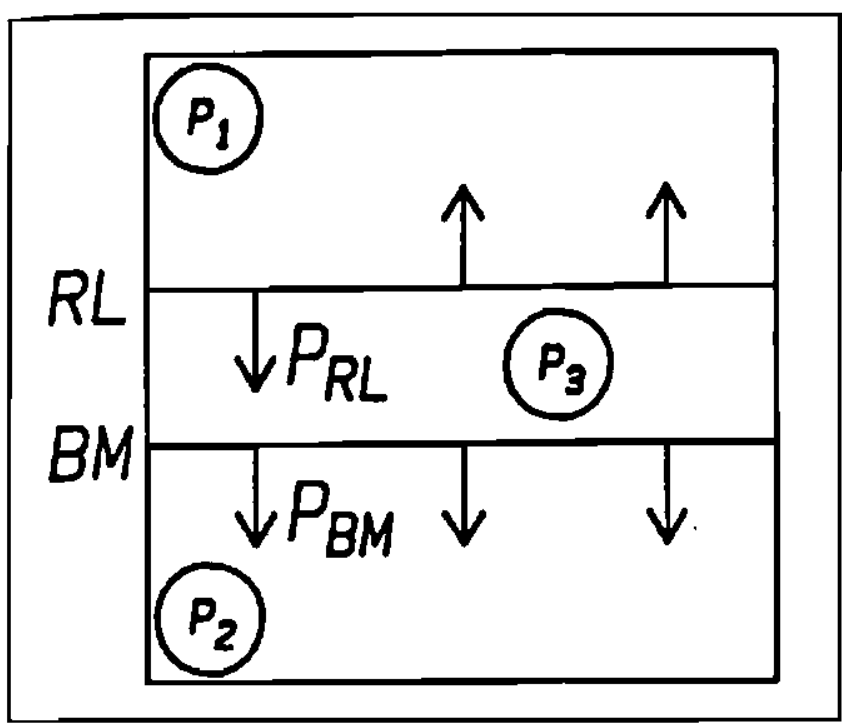

Figure 3. The "Sandwich Model" showing a filling of scala media (P3) with the organ of Corti, and two wedges on either side, the scala vestibuli (P2) and tympani (P1) (after de Boer, 1990, p.4).

credibility to what was previously a revolutionary statement, even in this information era. Moreover, they found that the vibration amplitudes at the level of the RL were maximal in the Hensen cells, decreasing towards the IHC. The steepness of the slope, i.e. the tuning curve was sharpest in the third row of $\mathrm{OHC}$, and shallowest in both the Hensen's cells and IHC. This led the experimenters to conclude that the OHC drove the RL. The vibrations of the BM were small compared to that of the OHC and RL and it would seem that the primary source of energy lies in movement of the OHC carrying the RL with it. In a sense, de Boer (1990) colludes with Khanna et al. (1986) by refuting the possibility of BM movement. This evidence is in sharp contrast to that of the stereocilia bending due to the mechanical motions of the BM.

For a closer examination of the role of RL mechanics, Zwislocki (1986) constructed a model with nonlinear coupling of the RL and tectorial membrane. He noted that nonlinearities observed were similar to those of the auditory nerve firing patterns. At low intensity levels, there was little or no distortion, at slightly higher intensities there was splitting of the peaks, and at even higher intensities, there was a phase shift initially of the order of $90^{\circ}$ and later $180^{\circ}$. He suggested that this nonlinearity could be due to the relative change in shearing movements between the tectorial membrane which is coupled to the OHC cilia and RL showing startlingly similar results after observing the rectified waveform of his construction.

\section{ACTIVE MICROMECHANICAL RESPONSES}

At a molecular level, the active mechanisms are less well understood but seem to have some basis in the contractile elements within the $\mathrm{OHC}$. Active lengthening and shortening of the OHC by stimulation of its actin filaments, have been demonstrated by several researchers in response to acoustic stimulation, drugs such as caffeine and potassium (Slepecky, Ulfendahl \& Flock, 1988; Ulfendahl, Flock \& Khanna, 1990) and electric currents (Zenner, Reuter, Plinkert \& Gitter, 1990).

Most recently, it has been suggested that these changes can also be induced by mechanical activity, such as that observed in the movement of the cochlear partitions (Kim, 1986; Ulfendahl et al., 1990). Kim (1986) therefore concluded, that it was important to examine the OHC whilst still within an intact Organ of Corti. By isolating the temporal bone from a guinea pig, they induced $\mathrm{OHC}$ shortening by applying caffeine. Not surprisingly, the $\mathrm{OHC}$ did indeed shorten, and it appeared that the caffeine triggered the release of calcium ions (a substance known to trigger contractile activity in other muscles) (Slepecky et al., 1988; Zenner, 1990). Moreover, the vibration amplitude of the organ of Corti, and tuning of the mechanical response was sharper in the presence of caffeine. Such conclusions led the experimenters to believe that the $\mathrm{OHC}$ were capable of influencing the mechanical response of the organ of Corti and therefore played a much more active role in frequency selectivity, non-linearity and tuning frequency of the cochlea than previously supposed.

Zenner et al. (1990) reports that $\mathrm{OHC}$ activity can also be stimulated by electric currents. Using a photodiode, they noted the longitudinal movements within the cylindrical cell body of the $\mathrm{OHC}$, that there is shearing of the stereocilia via a lateral sliding of the cuticular plate and simultaneous movement of both the $\mathrm{BM}$ and RL in the same direction. The motion of these stereocilia will cause OHC coupling with the IHC via the tectorial membrane and is termed the "fast motile response" (Zenner et al., 1990). It is unlikely that this response is due merely to the actin myosin interaction because of the short latency of the response according to Ashmore and Bronwell (1986 cited in Slepecky et al., 1988). Zenner et al. (1990) hypothesized that the displacement of the cuticular plate with the stereocilia may amplify the signal through closer coupling to the IHC via the tectorial membrane. The sharp focusing of these fast responses is thought to be responsible for the sharp tuning curves.

An alternative explanation was suggested by Kim (1986) in that these apically generated fast responses resulted in an oscillatory motion of the stereocilia. The idea of a bidirectional movement of the stereocilia has been revolutionary and illustrated through the examination of turtle hair cells (Fettiplace, 1985 cited in Nuttall, 1986). Using this information, Kim (1986) proposed that the forward transduction motion forms a feedback loop with the reverse motion. Similar thoughts were expressed by Clopton (1986) who felt that the voltage changes due to the stereocilia bending in one direction would result in greater excitation than in the other but does not suggest any specifics other than it may be sourced by the differential stiffness of the stereocilia depending upon direction of motion. However, other experimenters speculated that the asymmetrical arrangement of stereocilia at the apical ends of the $\mathrm{OHC}$ may account for the non-linearity of the cochlea (Khanna et al., 1990, p23).

A second, slower, motile mechanism of the $\mathrm{OHC}$ is also described wherein there is a slow depolarisation of $\mathrm{OHC}$. Shortening of the OHCs are observed, as is a reduction in the distance between the BM and RL. The origin of this response is thought to lie in the contraction of actin and myosin elements in the lateral wall of 


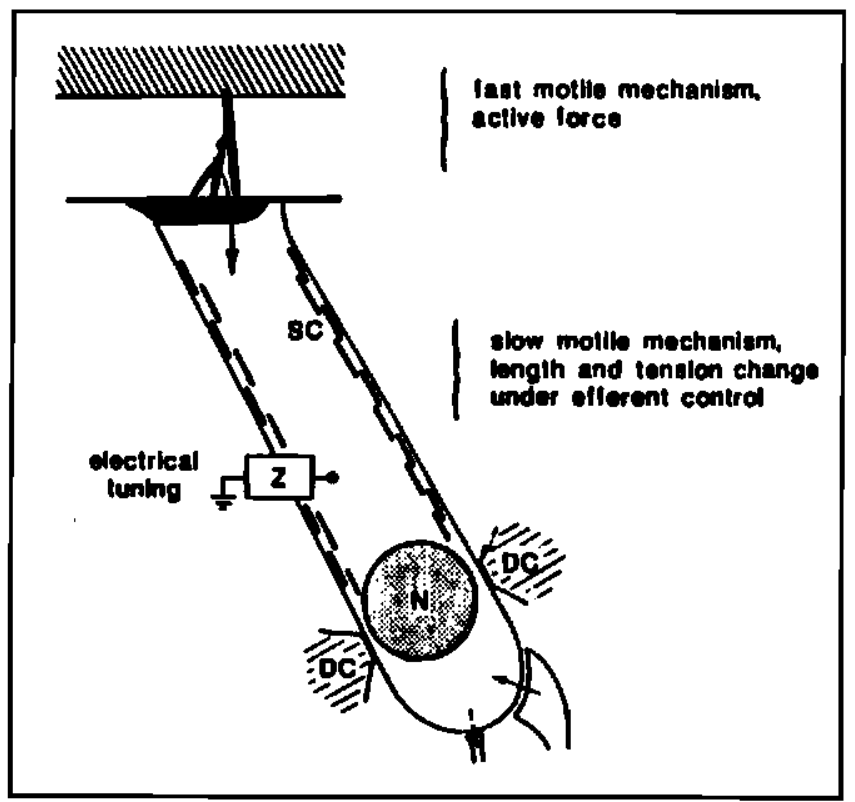

Figure 4. Schematic diagram of an outer hair cell illustrating proposed origins of the fast and slow motile responses and the apical areas rich in subcisternge (SC) (after Kim, 1986, p. 110).

the OHC (Zenner, 1986) unlike the actin-independent fast motile responses. $\operatorname{Kim}(1986)$ hypothesized that this slow motile response was responsible for the slow change in length of the OHC. Figure 4 illustrates the anatomical origins of these fast and slow responses suggested by Kim (1986).

There is much uncertainty over whether the fast, motile responses or the slower secondary ones give rise to the selectivity, nonlinearity and sensitivity of the cochlea although much research has been focused on the existence of efferent feedback loops. Efferent fibres from the oliviocochlear bundle are thought to control the fast, amplifying and selective action of the cochlea.

\section{EFFERENT CONTROL A SOURCE OF NONLINEARITY}

Contralateral masking is able to suppress ipsilateral DPOAE (Puel, Rebillard \& Pujol, 1990), and SOAE (Kujawa \& Glattke, 1989). Siegel \& Kim (1982) found that stimulation of the contralateral fibres arising from the oliviocochlear bundle (which synapse mainly with the OHC) could alter the strength of the distortion products suggesting $\mathrm{OHC}$ involvement in the generation of otoacoustic emissions. Already in 1962 (Fex cited in Warren III \& Lieberman, 1989) reported that the cochlear efferent system, arising from the oliviocochlear nucleus (OCN) could inhibit activity in the auditory afferent fibres. A schematic diagram of the anatomical pathway of the efferent fibres can be found in Figure 5 . However, Warren III et al. $(1989$, p.98) report that it had not been conclusively proven that this efferent system arose from the OCN only and they highlight three methods where contralateral sound can influence responses to the ipsilateral stimulus:

1. mechanical propagation of the acoustic stimulus via bone conduction to the contralateral cochlea;

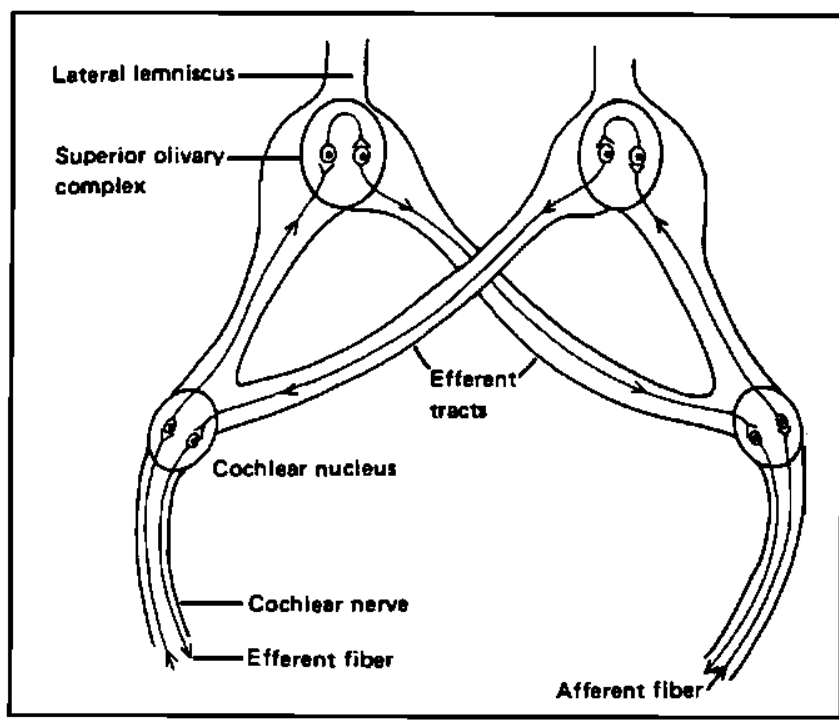

Figure 5. The cochlear efferent system originating from the oliviocochlear nucleus in the superior olivary complex.

2. some neural feedback system of which there could be three possibilities: (a) via the middle ear reflex muscles (stapedius and tensor tympani); (b) the oliviocochlear efferent system and (c) autonomic efferents to blood vessels within the spiral lamina:

3. there may be humoral agents released when the ear is acoustically stimulated and which travel via the circulatory system to the opposite side.

The idea of accoustic crosstalk was eliminated since the intensity of the sound was always less than the level required for contralateral excitation. Likewise, the likelihood of blood circulating agents was also discounted because of the time necessary to travel to the opposite cochlea. The three remaining neural feedback systems appear to be the most feasible explanation. Both Warren III et al. (1989) and Puel et al. (1990) in their studies severed the stapedius and tensor tympani muscles to ensure that the middle ear muscles did not participate in this phenomenon. Finally, through a process of elimination Warren III et al. (1989) state that the oliviocochlear system is the most likely originator of the efferent feedback loop since they argue unconvincingly that when there is removal of the cervical synpathetic system, there is a decrease in the N1 action potential (Hultzcrantz et al., 1982 cited in Warren III et al., 1989) suggesting to them that the autonomic nervous system was in fact used to enhance auditory sensitivity - an idea first suggested by Beickert et al., 1956 (cited in Zemlin, 1982) although to date, there is still no empirical evidence.

Warren III et al. (ibid) therefore attributed this feedback process to the inhibitory cochlear efferents innervating the $\mathrm{OHC}$ and originating from the OCN in the central auditory pathway. They further postulate that the medial OCN was responsible for this action because they comprise large, myelinated nerves whereas the lateral OCN consists of largely smál, unmyelinated neurones from experiments comparing myelinated and unmyelinated responses to electrical excitation (Gifford \& Guinam, 1987).

The idea of a closed feedback loop system and cochlear 


\section{A New Look at Cochlear Mechanics}

efferents to modulate OHC motility is also proposed by Puel et al., (1990), Kim (1986) and Bronwell (1990). Animal observations by Lieberman (1988 cited in Warren III et al., 1989 and in Froehlich, Collet, Valatz \& Morgon, 1993) show that auditory afferent stimuli can excite the efferent fibres arising from the medial OCN i.e. large, unmyelinated efferents leading to the OHC (Warr et al., 1986 cited in Dannhof \& Bruns, 1993). Moreover, these medial OCN efferent fibres could inhibit activity in the contralateral auditory efferent fibres (Lieberman 1988 cited in Warren III et al., 1989).

Johnstone et al. (1986) suggested that these efferents were used to return the stereocilia to its normal position after being bent in an excitatory manner by the movement of the BM (p.151). In another paper with Rajan (1983), he also noted the protective effects of stimulating the efferent system during TTS and cited this as evidence of their role in the feedback loop.

The high frequency selectivity of the bat has always sparked interest and its efferent innervation was of particular interest to Xie, Henson, Bishop \& Henson (1993). They identified a greater number of OHC terminals in areas known to be associated with sharp frequency tuning and selectivity in the bat. In study of mammals such as the cat (Lieberman \& Brown, 1986) and the guinea pig (Hashimoto \& Kimura, 1987), the trend is towards a greater density of efferent terminals in the basal and middle regions with less in the apical regions. A comparison of vibration responses of the third and fourth turn in the guinea pig cochlea show that there is a sharper tuning in the more basal ends (Khanna et al., 1990) - an observation confirmed by using in vivo measurements of the cat cochlea (Lieberman, 1982 cited in Neely \& Kim, 1986). A relationship between greater frequency sensitivity and efferent terminal density is therefore implied by these observations (Xie et al., 1993).

Not only is there a regional variation in efferent innervation, but also differences across the rows of $\mathrm{OHC}$ noted by several researchers' (Fex et al. 1982; Simmons et al. 1990; Fex \& Altschuler 1984). Initially, the density of efferent fibres along the first row of $\mathrm{OHC}$ was thought to be a consequence of developmental patterns but it has been suggested that this is not so. The population density may be related to amount of synaptic activity and possibly areas of sharp tuning (Xie et al., 1993). However, this in sharp contrast to findings by Khanna et al. (1990) who found that the vibration amplitude and frequency response was sharpest in the third row of OHC. However, Xie et al. (1993) acknowledges that the role of efferent terminals are still unclear and subject to much conjecture.

A lone voice amongst this excitement about efferent feedback loops is that of Dolan \& Nuttall (1989) who suggested that there may be no feedback loop or efferent control system since they observed changes in IHC potentials following contralateral stimulation to be constant in amplitude and instantaneous in activation. They remark that such a feedback system would not be able to be activated within such a short latency and with such constant magnitude.

\section{COCHLEAR BIOCHEMISTRY}

The bending of the cilia is thought to generate an electric current (depolarisation) along their apical ends which controls the release of neurotransmitter vesicles at the base of the hair cell (Clopton, 1986) and supposedly initiates firing of the auditory nerve (Nuttall, 1986). This characteristic of the $\mathrm{OHC}$ in which they are capable of bending in both directions with force distinguishes it from skeletal muscle in which contractions can only be directed in a single direction, whilst the relaxation phase is passive and does not exert force (Bronwell, 1990). Lim (1986) is more specific, and suggests that the stereocilia bending in the excitatory direction only will result in the initiation of neural impulses.

Nevertheless, depolarisation of drug-induced contractions result in an increase in intracellular $\mathrm{Ca}^{2+}$. Nuttall (1986) speaks about the "gating of ions" (p.29), or a physical channel through the cell membrane permitting the passage of ions through. Zenner (1986) demonstrated that by bathing the hair cells in variable ionic concentrated fluid could result in motile responses of the hair cells therefore suggesting as Nuttall (1986) does, that extracellular ions are responsible for motility of the cilia. Ikeda \& Takasaka (1993) more specifically reported that the increase in intracellular $\mathrm{Ca}_{2+}$ was due to transmembrane influx of calsium from the surrounding endolymph and release from the apical cisterns and Hensen's cells.

Contradictory evidence is presented by Slepecky et al. (1988) in a study of the effects of tetracaine, a local anaesthetic when they found that it inhibited potassium and calcium-induced contractions in muscle but it did not affect contractions of the $\mathrm{OHC}$ when applied extracellularly. This led them to the believe that the increase in cellular calcium was of intracellular origin and did not arise from an influx through the permeable cell membrane. Kim (1986) postulated that this slow response was mediated in the area between the cuticular plate and the OHC nucleus - an area characterised by a large number of these subsurface cisternae.

The finding of gamma amino-buytyric acid (Eybauling et al., 1988 cited in Dannhof et al., 1993) and acetylcholine receptors (Zenner et al., 1990) at the synapses of the OHC, suggested that efferent nerves could stimulate release of inositol-trisphosphate which would control the release and uptake of calcium ions into the cytoplasm and modulate $\mathrm{OHC}$ contractions. Recent discovery of other neurotransmitters such as choline acetyltransferase and glutamatee decarboxylase present in all OHC efferents and along the entire cochlea (Dannhof et al., 1993) suggested that they perform a similar function.

It is unlikely that the fast motile responses required the mediation of intracellular $\mathrm{Ca}_{2+}$ (Zenner et al., 1987 cited in Ikeda \& Takasaka, 1993) because of its relative independence of adenosin triphosphate (ATP) involvement (Kachar et al., 1986 cited in Slepecky et al., 1988).

De Boer (1990) speculates that mechanical energy within the scala media or tectorial membrane could be released into the Organ of Corti, or that the energy source could be electrical or even chemical, and idea that appeals to Neely and Kim (1986) as well. They guessed that the source of this energy was electrochemically obtained from the surrounding endolymph. ATP is necessary in all biological systems as an energy source necessary for the maintenance of the system. An active cochlea implies that energy needs to be added to the system and Schacht (1986) reasons 
that there is no evidence that the cochlea differs from any other system in the body, and that ATP is formed through energy metabolism procedure called oxidative phosphorylation. ATP is a phosphate compound whose molecular bonds are rich in energy which can be released when required (McGilvery \& Goldstein, 1979). Bronwell (1990) strongly disagrees with Schacht (1986) stating that "the movements result from direct conversion of electrical potential energy to mechanical energy come from experiments that demonstrate movements even after cellular stores of ATP are depleted" (p.84). By so doing, he is specifically stating that the physiology of the cochlea is very different to any other body system by not requiring ATP. He states that ATP is produced in stria vascularis and used to drive peripheral cells and not OHC specifically.

Davis (year unknown, cited by Schacht, 1986) was the first to present his "battery theory" where he cites stria vascularis as being the source of this energy and for this reason Schacht (1986) surmises that the cochlea has an unusually low metabolic rate in comparison to other sensory systems because of the contribution of stria vascularis although the exact relationship has yet to be elucidated. Four years later, Bronwell suggested that the stria vascularis is the source of a silent current of potential energy (1990) and it is this current that stimulates the motility of the $\mathrm{OHC}$. OHC are therefore indirectly fueled by ATP via the stria vascularis.

\section{RETURN TO THE PASSIVE MODEL}

Lechner (1993) correctly states that the activity of the intact BM is still unclear. Dancer (1992), from a review of the literature also suggests the re-examination of the BM. If the cochlea is as active as suggested by the previous research, Clopton (1986) argues that such an undamped system would be highly unstable and would have a long release time with oscillations continuing for several seconds. This instability is acknowledged by Bronwell (1990) who rationalises that it is these very oscillations which will trigger SOAE.

By comparing the latency between the cochlear microphonic and the input stimulus obtained via direct measurements and those calculated from the Zwislocki travelling wave theory, Dancer (ibid) was able to conclude that measurements were significantly smaller than those calculated, as illustrated in Figure 6 . He concluded that the BM was stimulated as a whole immediately and that the BM acted as a Helmholtz resonator at least at frequencies below the characteristic frequency, a theory subscribed to more than a century before. However, he is sceptical about the use of the onedimensional longwave model proposed by Zwislocki (1948 cited in Zemlin, 1982) because the expectations of a long latency required by this model are not met by the short experimental measurements. They concluded . that this bank of resonators was a passive phenomenon until the point of characteristic frequency of the BM, where $\mathrm{OHC}$ are thought to contribute towards some active processing superimposed upon a passive hydromechanical phenomenon.

Clopton (1986) also subscribes to this view, in which the passive role of $\mathrm{BM}$ resonance is coupled with the active but independent resonation of the tectorial membrane and hair cells. Lizard hair cells were examined

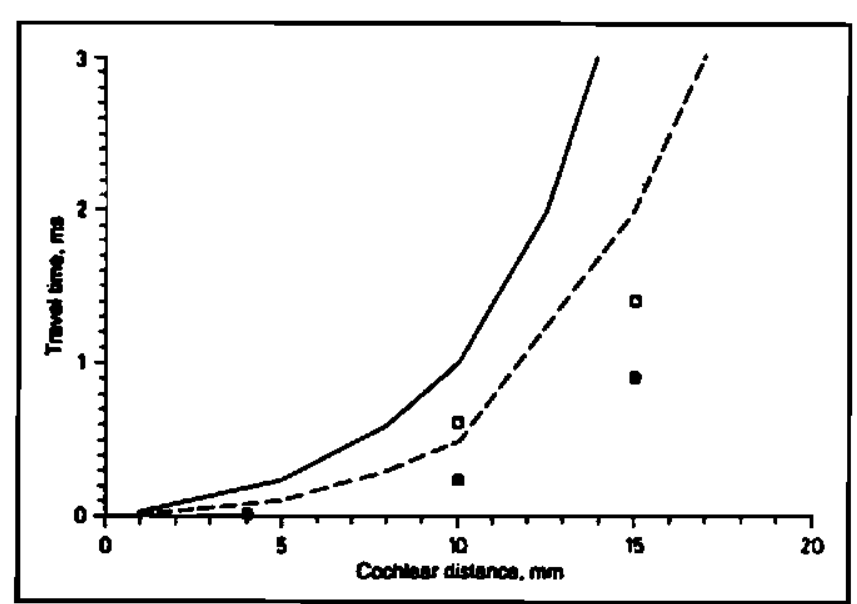

Figure 6. Time taken for a wave to traverse the length of a guinea pig cochlea. Theoretically calculated times $(\ldots)$ are contrasted with actual latencies ( $\square$ ) (after Dancer, 1992, p. 305).

by Peake \& Ling (1980) and they found that the BM vibrated as a whole in response to acoustic stimuli and no travelling wave was generated.

Using a newly developed piezopolymer transducer to measure BM displacement, Lechner (1993) constructed a hydromechanical model of the ear and concluded from his observations that the longitudinal stiffness of the BM could provide differential response characteristics, seemingly providing more experimental evidence that perhaps these traditional theories were not to be discarded so quickly.

Kolston, Viergever, de Boer \& Diependaal (1989) criticise the assumption of active elements in the cochlea since it was based on observed broad mechanical tuning together with the fine frequency selectivity of the neural responses. In comprehensive cochlea model based on an anatomical evidence, Kolston et al. (1989) suggest that the BM is divided into an arcuate and pectinate zone (refer Figure 7).

The motion of the arcuate zone was influenced by the

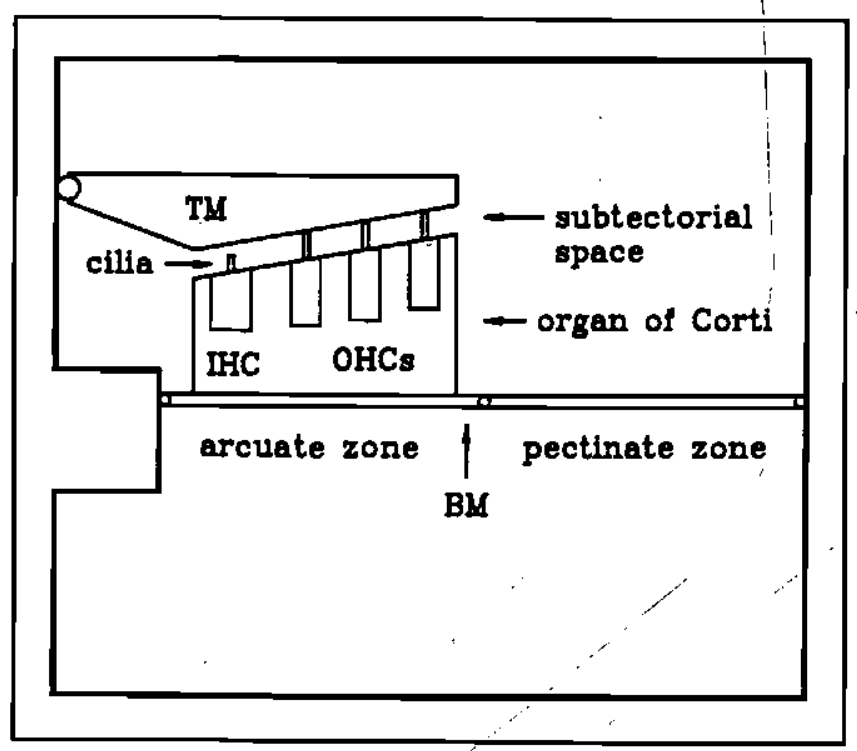

Figure 7. Schematic diagram showing the division of the basilar membrane (BM) into an arcuate and pectinate zone (after Kolston et al., 1989, p. 134). 
organ of Corti and tectorial membranes. They postulated that the supporting cells in the pectinate zone acted as feedback mechanisms to the OHC to enable them to control their impedance and consequently indirectly controlling BM motion. This theory is interesting in that it is able to suggest a function for the supporting cells as well which up to now has been speculated to be purely supportive and nutritive (Engström, 1982). This theory is also able to explain the contrast between broad tuning measured in the cochlea and the sharpness of the acoustic nerve response (Johnstone et al., 1986). The authors argue that the probes utilised measured average BM response, largely the response of the pectinate zone. Their conclusion is that sharp frequency selectivity of the cochlea can exist without the use of active elements, if the effect of the arcuate zone were to be taken into account.

Data from Khanna \& Leonard (1982 cited in Neely \& $\mathrm{Kim}, 1986$ ) speculate that there is a linear relationship between BM displacement and excitation of hair cells at levels near threshold. De Boer (1983) then extended this idea by suggesting that nonlinearity only becomes evident at high intensities. This idea correlates well with the hypothesis that only excessive gain of the amplifier would generate SOAE (Neely \& Kim, 1986).

Several theories subscribe to the coexistence of a passive and active element in the cochlea, but differ in their division of the roles - be it along the threshold of frequency continuum.

\section{AND SO ...}

Despite this wealth of data about the $\mathrm{OHC}$, what about the inner hair cells (IHC). Spoendlin (1969 cited in Engström et al., 1982) reports that $90-95 \%$ of the afferent nerve fibres innervate the IHC. Moreover, most of the auditory information carried by the auditory nerve arise from the IHC (Pfingst, 1986). The purpose of the IHC seems to be to detect the stimulus and mimic the characteristics of the acoustic nerve (de Boer, 1983; Nuttall, 1986). How the (stereocilia of these cells are displaced is still questionable although there are postulations that it may be through the viscous forces of the surrounding fluids (Nuttall, 1986) or influence from the active mechanical OHC. Brown \& Nuttall ( 1984 cited in Nuttall, 1986) found that the OHC has sufficient active energy to set the inner hair cell cilia in motion. The exact nature of the coupling between $\mathrm{OHC}$ and IHC is still one of the most perplexing question in auditory physiology since it has been generally accepted that there is no direct mechanical coupling via the tectorial membrane.

Nevertheless, $\operatorname{Lim}(1986)$ in his detailed review of the microanatomy of the cochlea reports on the existence of IHC imprints on the basal surface of the tectorial membrane. He acknowledges that these are not as distinct and consistent in appearance as those of the $\mathrm{OHC}$ but at the same time states that the possibility, of IHC (especially those at the apical end) coupling to the tectorial membrane albeit loose should not be ignored. Such evidence suggests that there could be mechanical coupling of $\mathrm{OHC}$ responses to the IHC.

By anatomically contrasting the $\mathrm{IHC}$ and $\mathrm{OHC}$, a number of differences between these two sensory structures can be noted, most markedly the innervation sys- tem (greater number of afferents IHC), tectorial membrane coupling and location along the BM (Lim, 1986, p.142). IHC tends to be located on the immobile portion of the BM whilst $\mathrm{OHC}$ are found on the lateral, more mobile portions. This suggests that the $\mathrm{OHC}$ could be responsible for the active mechanics of the cochlea whilst the IHC acts as the passive transducer.

The role of the supporting cells in auditory perception has also been questioned although evidence is still scanty. Traditionally, they have been considered to provide a supporting framework, form a boundary between the endolymph and perilymph, formation of the tectorial membrane and phagocytosis of cell debris (Engström et al., 1982; Oesterle \& Dallos, 1989). Oesterle \& Dallos (1986) found that both alternating and direct current were compared and the amplitude of the currents were found to be dependent upon the cell location. The closer the cell was situated to the IHC, the larger the direct current component. They postulated that their role could be in the regulation of neurotransmitter concentration in the intercellular spaces (p.231). In a subsequent paper on the same subject, the experimenters concluded that the potentials measured in the supporting cells arise from the electric currents generated by the hair cells and also show a reflection of the tuned responses of the hair cells.

\section{CONCLUSIONS}

Research in the area of cochlear micromechanics is still ongoing although much information has been gained through the discovery of otoacoustic emissions. Recording of spontaneous and evoked emissions revived the concept that the cochlea could be active, whilst the discovery of distortion product emissions confirmed the presence of nonlinearity in the cochlea. The third problem facing biophysicists was the high frequency selectivity of the IHC and VIII nerve when compared to the broad tuning curves of the BM. Subsequent research has focussed mainly on the resolution of these three aspects of cochlear physiology.

There is a wealth of fragmentary experimental data examining isolated cochlear behaviour under certain conditions, but the assimilation of this data into a cohesive cochlear model is still elusive. A major problem lies in the construction of a mechanically active cochlear model which is intrinsically unstable hampering investigators (de Boer, 1983, p.572) as well as the limited in vivo measurements possibly causing the seemingly contradictory data.

Regardless of these difficulties, there seems to be increasing concensus over several issues:

(a)that non-linearity exists at several levels - the basilar membrane, the mechanical transduction into potentials and between the hair cell potentials themselves (Eggormont, 1993);

(b)that there is an active process occurring within the cochlear (Davis, 1983) primarily mediated by the outer hair cells (Kim, 1986);

(c) that the origin of the emissions are the electromotility of the OHC (Bronwell, 1990) as observed by the obliteration of these responses following noise-exposure, salicylate ingestion and other insults;

(d)that the efferent feedback loop (Xie et al., 1993) and in particular the neurotransmitters (Zanner et al., 
1990) play a critical role in this. Such observations would explain the sharp tuning curves of the cochlea and the presence of otoacoustic emissions and the pivotal role the $\mathrm{OHC}$ plays.

Nevertheless, some authors have cautioned against the quick dismissal of the traditionally held theories of hearing and suggest the presence of some crucial passive response of the cochlea occurring concomitantly (Dancer, 1992). There is an overwhelming mass of experimental data on cochlear mechanics and each publication brings with it a new dimension. This paper serves merely to highlight the current trends, but this arena is eternally in a state of flux. Undoubtedly, the cochlea is truly a sensitive, selective and secretive instrument!

\section{REFERENCES}

Bronwell, W.E. (1990). Outer Hair Cell Electromotility and Otoaustic Emissions, Ear and Hearing, 11, 2, 82-92.

Carlisle, L. (1986). Anatomy and Pathology of the Inner Ear. Seminars in Hearing, 7, 1, 1-14.

Clopton, B.M. (1986). Micromechanics of the Cochlea. Seminars in Hearing, 7,1, 15-26.

Dannhof, B.J. \& Bruns, V. (1993). The innervation of the organ of Corti in the rat. Hearing. Research, 66, 8-22.

Dancer, A. (1992). Experimental Look at Cochlear Mechanics. Audiology, 31, 301-312.

Davis, H. (1983). An active process in cochlear mechanics. Hearing Research, 9, 79.90.

de Boer, E. (1983). No sharpening? A challenge for cochlear mechanics. Journal of Acoustical Society of America, 73, 2 , 567-573.

de Boer, E. (1990). Wave Propagation, Activity and Frequency Selectivity in the Cochlea. In F. Grandori, G. Cianfrone, D.T. Kemp (Eds): Cochlear Mechanisms and Otoacoustic Emissions, Advances in Audiology. Basel, Karger, 7, 1-12.

Dolan, D.F. and Nuttall, A. (1989). Inner hair cell response to tonal stimulation in the presence of broadband noise. Journal of Acoustical Society of America, 86, 3, 1007-1012.

Eggermont, J.J. (1993). Wiener and Volterra analyses applied to the auditory system. Hearing Research. 66, 177-201.

Engström, H. and Engström, B. (1982). Hearing: Some Notes on Structure and Function, Topholm and Westermann, Denmark.

Fex, J., Altschuler, R.A., Wenthold, R.J. \& Parakkal, M.H. (1982). Aspartate aminotransferase immunoreactivity in cochlear of guinea pig. Hearing Research, 7, 149-160.

Fex, J. \& Altschuler, R.A. (1984). Glutamic acid decarboxylase immunoreactivity of olivocochlear neurones in the organ of Corti of guinea pig and rat. Hearing Research, 15, 123. 131.

Froelich, P., Collet, L., Valatz, J.L. \& Morgon, A. (1993). Sleep and active cochlear micromechanical properties in human subjects. Hearing Research, 66, 1-7.

Gifford, M.L. \& Guinam, J.J. (1987). Effects of electrical stimulation of medial oliviocochlear neurons on ipsilateral and contralateral cochlear responses. Hearing Research, 29, 179-194.

Glattke, T.J. \& Kujawa, S.G. (1991). Otoacoustic Emissions. American Journal of Audiology, 29-40.

Grandori, F., Cianfrone, G. \& Kemp, D.T. (1990). Preface to Cochlear Mechanisms and Otoccoustic Emissions. Advances in Audiology. Basel, Karger VII-VIII.

Harisson, R.V. \& Evans, E.F. (979). Cochlear fibre responses in guinea pigs with well defined cochlear lesions. Scandinavian Audiology Suppl, 9, 83-92.

Hashimoto, S. \& Kimura, R.S. (1987). Computer-aided three dimensional reconstruction and morphometry of the outer hair cells of the guinea pig cochlea. Acta Otolaryngologica, $103,64-74$.

Hultzcrantz, E., Nuttall, A.L., Brown, M.C. \& Lawrence, M. (1982). The effect of cervical sympathectomy on cochlear physiology, Acta Otolaryngologica, 94, 439-444

Ikeda, K. \& Takasaka, T. (1993). Confocal laser microscopical images of calcium distribution and intracellular organelles in the outer hair cell isolated from the guinea pig cochlea. Hearing Research, 66, 169-176.

Johnsen, N.J. \& Elberling, C. (1982). Evoked Acoustic Emissions from the Human Ear: I. Equipment and Response Parameters. Scandinavian Audiology, 11, 3-12.

Johnstone, B.M., Patuzzi, R. \& Yates, G.K. (1986). Basilar membrane measurements and the travelling wave. Hearing Research, 22, 147-153.

Kemp, D.T. (1978). Stimulated acoustic emissions from within the human auditory system. Journal of the Acoustical Society of America, 64, 5, 1386-1391.

Kemp, D.T. (1979). Evidence of mechanical nonlinearity and frequency selective wave amplification in the cochlea. Archives of Otorhinolaryngology, 244, 37-45.

Khanna, S.M. \& Leonard, D.G.B. (1986). Measurement of basilar membrane vibrations and evaluation of cochlear condition. Hearing Research, 23, 55-70.

Khanna, S.M., Ulfendahl, M. \& Flock, A. (1990). Cellular Mechanical Responses in the Cochlea. In F. Grandori, G. Cianfrone, D.T. Kemp (Eds): Cochlear Mechanisms and Otoacoustic Emissions. Advances in Audiology. Basel, Karger, 7, 13-26.

Kim, D.O., Siegel, J.H. \& Molnar, C.E. (1979). Cochlear nonlinear phenomena in two-tone response. Scandinavian Audiology Suppl, 9, 63-81.

Kolston, P.J., Viergever, M.A., de Boer, E. \& Diependaal, R.J. (1989). Realistic mechanical tuning in the micromechanical cochlear model. Journal of Acoustical Society of America, 81, 1, 133-139.

Kujawa, S.G. \& Glattke, T.J. (1989, October). Influence of contralateral acoustic stimulation on spontaneous otoacoustic emissions. ASHA, 31,123

Lechner, T.P. (1993). A hydromechanical model of the cochlea with nonlinear feedback using PVF , bending transducers. Hearing Research, 66, 202-212.

Lieberman, M.C. \& Brown, M.C. (1986). Physiology and anatomy of single oliviocochlear neurons in the cat, Hearing Research, 24, 17-36.

Lim, D.J. (1986). Functional structure of the organ of Corti: a review. Hearing Research, 22, 117-146.

McGilvery, R.W. \& Goldstein, R. (1979). Biochemistry: A Functional Approach, 2nd edition, WB Saunders Co., Japan.

Neely, S.T. \& Kim, D.O. (1986). A model for active elements in cochlear biomechanics, Journal of Acoustical Society of America, 79, 5, 1472-1480.

Nuttall, A.L. (1986). Transduction and Frequency Tuning in Hair Cells. Seminars in Hearing, 7, 1, 27-44.

Oesterle, E. \& Dallos, P. (1986). Intracellular recordings from supporting cells in the organ of Corti. Hearing Research $22,229-232$.

Oesterle, E. \& Dallos, P. (1989). Intracellular recordings from supporting cells in the guinea-pig cochlea: AC potentials, Journal of Acoustical Society of America, 86, 3, 1013-1032.

Peake, W.T. \& Ling, A. (1980). Basilar membrane motion in the alligator lizard: its relation to tonotopic organisation and frequency selectivity, Journal of Acoustical society of America, 67, 1736-45.

Pfingst, B.E. (1986). Encoding of Frequency and Level Information in the Auditory Nerve. Seminars in Hearing, $7,1,45-64$

Pickles, J.O. (1982). An Introduction to the Physiology of Hearing, Academic Press, London.

Probst, R., Antonellia, C. \& Pieren, C. (1990). Methods and Preliminary Results of Measurements of Distortion Product Otoacoustic Emissions in Normal and Pathological ears. In F. Grandori, G. Cianfrone \& D.T. Kemp (Eds): Cochlear Mechanisms and Otoacoustic Emissions, Advances in Audiology. Basel, Karger, 7, 117-125.

Puel, J.L., Rebillard, G. \& Pufol, R. (1990), Active Mechanisms and Cochlear Efferents. In F. Grandori, G. Cianfrone \& D.T Kemp (Eds): Cochlear Mechanisms and Otoacoustic Emissions, Advances in Audiology. Karger, 7, 156-163.

Rajan, G. (1990). Crossed cochlear influences on monaural temporary threshold shifts, Hearing Research, 12, 185.197.

Rossi, G. (1990). Intracochlear Mechanisms involved in the generation of Delayed Evokéd Otoacoustic Emissions. In F. Grandori, G. Cianfrone \& D.T. Kemp (Eds): Cochlear Mechanisms and Otoacoustic Emissions. Advances in 
Audiology. Basel, Karger, 7, 180-187.

Schacht, J. (1986). Biochemistry of Cochlear Function and Pathology. Seminars in Hearing, 7, 1, 101-115.

Siegel, J.H. \& Kim, D.O. (1982). Efferent neural control of cochlear mechanics? Olivocochlear bundle stimulation affects cochlear biomechanical nonlinearity. Hearing Research, 6, 171-182.

Simmons, D.D., Manson-Gieseke, L., Hendrix, T.W. \& McCarter, S. (1990). Reconstructions of efferent fibres in the postnatal hamster cochlea, Hearing Research, 15, 113122.

Slepecky, N., Ulfendahl, M. \& Flock, A. (1988). Effects of caffeine and tetracain on outer hair cell shortening suggest intracellular calcium involvement. Hearing Research, 32 11-22.

Ulfendahl, M., Flock, A. \& Khanna, S.M. (1990). Cochlear Mocromechanics - From Isolated Cells to the Intact Hearing Organ. In F. Grandori, G. Cianfrone \& D.T. Kemp (Eds): Cochlear Mechanisms and Otoacoustic Emissions. Advances in Audiology. Basel, Karger, 7, 27-34.

Voldrich, L. (1978). Mechanical Properties of Basilar Membrane. Acta Otolaryngologica, 86, 331-335.

Warren III, E.H. \& Lieberman, M.C. (1989). Effects of contralateral sound on auditory nerve responses: I Contributions of cochlear efferents. Hearing Research, 37 89-104.
Xie, D.H., Henson, M.M., Bishop, A.L. \& Henson, O.W. (1993). Efferent terminals in the cochlea of the mustached bat: Quantitative data. Hearing Research, 66, 81-90.

Zemlin, W.R. (1982). Speech and Hearing Science - Anatomy and Physiology, 2nd edition, Prentice-Hall Inc, New Jersey.

Zenner, H.P., Zimmerman, U. \& Schmitt, U. (1985). Reversible contraction of isolated mammalian cochlear hair cells, Hearing Research, 18, 127-133.

Zenner, H.P. (1986). Motile responses in outer hair cells, Hearing Research, 22, 83-90.

Zenner, H.P., Reuter, G., Plinkert, P.K. \& Gitter, A.H. (1990). Fast and Slow Motility of Outer Hair Cells in vitro and in situ. In F. Grandori, G. Cianfrone \& D.T. Kemp (Eds): Cochlear Mechanisms and Otoacoustic Emissions. Advances in Audiology. Basel, Karger, 7, 35-41.

Zwislocki, J.J. (1986). Are nonlinearities observed in firing rates of auditory nerve afferents reflections of a nonlinear coupling between the tectorial membrane and the organ of Corti?. Hearing Research, 22, 217-221.

\section{ADDRESS CORRESPONDENCE TO:}

C Jardine, Department of Speech Pathology and Audiology, University of the Witwatersrand, $P O$ Wits, 2050. 


\section{Offices in Melville and Johannesburg}

\section{TINNITUS MASKERS}

Tinnitus is usually experienced as a ringing, hissing or buzzing sound in the ear or in the head. It is commonly associated with a mild hearing loss in the high frequencies.

According to the American Tinnitus Association almost 5\% of the American population suffers from tinnitus in its severe form and millions more are afflicted to a lesser degree. We have no reason to believe that the situation is any different in South Africa. Surveys have shown that the most effective source of relief is a tinnitus masker.

Acoustimed's tinnitus masker is an In-The-Canal device which uses a specially designed amplifier module capable of amplifying up to $20000 \mathrm{~Hz}$. For high frequency tinnitus the masker can be adjusted to provide as much as 70dB SPL of masking noise at frequencies above $6000 \mathrm{~Hz}$. Our experience with tinnitus masking has shown that a high frequency masker can provide effective masking with least awareness of the masking noise. In exceptional cases the masking noise is inaudible.

The presence of a masker interferes with the acoustic characteristics of the ear canal causing, in effect, a mild high frequency hearing loss. All maskers must, therefore, provide some acoustic gain in the region of $3000 \mathrm{~Hz}$ even if the patient's hearing is completely normal. Where necessary the masker will additionally compensate for the hearing loss which is typically associated with tinnitus.

Because each masker is custom-built it is necessary to determine the nature of the tinnitus and obtain a reasonable prognosis prior to manufacture. For this purpose we use a number of instruments including a computer program which simulates multi-frequency tinnitus.

For more information please telephone $337-2977$ or $726-2430$.

Registered Hearing Aid Acousticians: D. A. Smith - D. Christodoulides - L. Williams 